\title{
Step-by-step total pelviperitonectomy with modified posterior pelvic exenteration
}

\author{
Alvaro Tejerizo-Garcia (1) , ${ }^{1,2}$ Alejandro Olloqui, ${ }^{1}$ Gregorio Lopez, ${ }^{1,2}$ Carmen Alvarez-Conejo, ${ }^{1}$ \\ Oscar Caso-Maestro, ${ }^{3}$ Alvaro Diez ${ }^{1}$
}

\begin{abstract}
- Additional material is published online only. To view please visit the journal online (http://dx.doi.org/10.1136/ijgc2019-000984).
\end{abstract}

${ }^{1}$ Gynecologic Oncology and Minimally Invasive Gynecologic Surgery Unit (Department of Obstetrics and Gynecology), Hospital Universitario 12 de Octubre, Madrid, Comunidad de Madrid, Spain

${ }^{2}$ Instituto de Investigación Hospital 12 de Octubre, Madrid, Comunidad de Madrid, Spain ${ }^{3}$ Department of General Surgery Unit of HBP Surgery and Abdominal Organs Transplantation, Hospital Universitario 12 de Octubre, Madrid, Comunidad de Madrid, Spain

\section{Correspondence to Dr Alvaro Tejerizo-Garcia, Gynecologic Oncology and Minimally Invasive Gynecologic Surgery Unit (Department of Obstetrics and Gynecology), Hospital Universitario 12 de Octubre, Madrid 28041, Spain; alvaro.tejerizo@salud.madrid. org}

Accepted 3 December 2019 Published Online First 6 January 2020

Check for updates

C IGCS and ESGO 2020. № commercial re-use. See rights and permissions. Published by BMJ.

To cite: Tejerizo-Garcia A, Olloqui A, Lopez G, et al. Int J Gynecol Cancer 2020;30:558.
The fundamental aim of advanced ovarian cancer surgery is to obtain complete cytoreduction. Due to the pelvic anatomy, en bloc removal of the uterus, adnexa, rectum, and surrounding peritoneum is mandatory. ${ }^{1}$

The effect of complete cytoreduction on survival in patients with advanced ovarian carcinoma has been demonstrated in many studies. In our opinion, radical oophorectomy is a technique that helps us achieve complete cytoreduction and minimizes bleeding, with a manageable rate of intra-operative and postoperative complications. ${ }^{234}$

To easily understand this complex surgery, our video shows 10 systematized steps to achieve complete pelvic cytoreduction with total pelviperitonectomy and modified posterior exenteration.

Our patient was a 50-year-old woman with a good functional status and nutritional state. She had no co-morbidities and underwent primary cytoreduction surgery and posterior adjuvant chemotherapy. The peritoneal carcinomatosis index calculated was 8.

The steps of the technique are as follows:

Lateral approach:

Step 1: Defining the surgical territory.

Step 2: Lateral peritonectomy.

Step 3: Development of lateral avascular spaces, paravesical and lateral pararectal space.

Step 4: Uterine artery ligation.

Step 5: Development of medial pararectal space.

Anterior approach:

Step 6: Anterior peritonectomy. Vesico-uterine and vesico-vaginal space development.

Step 7: Ureteral tunnel development

Step 8: Anterior and lateral parametrium section. Colpotomy.

Step 9: Rectovaginal space development.

Posterior approach:

Step 10: Pre-sacral space development. Sigmoid and distal rectum section.

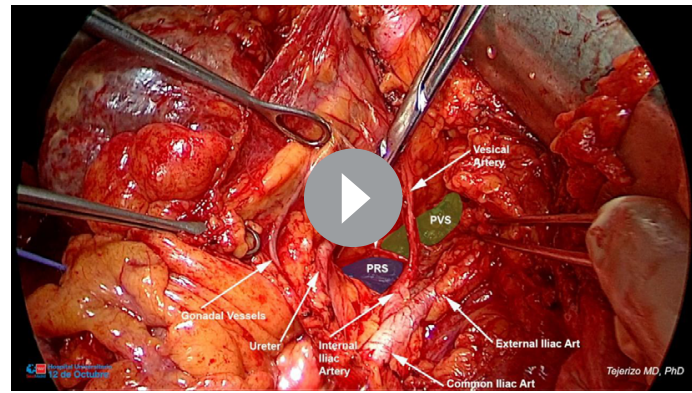

video 1

Contributors AT-G, AO, GL, CA-C and AD conceived the idea of the video $A T-G, G L$, and $O C-M$ performed the surgery. AT-G, $A 0$, and $A D$ made the video and sound editing. $A 0, C A-C$ and $A D$ wrote the abstract. All authors revised, discussed, and contributed to the final result.

Funding The authors have not declared a specific grant for this research from any funding agency in the public, commercial or not-for-profit sectors.

Competing interests None declared.

Patient consent for publication Not required.

Provenance and peer review Not commissioned; externally peer reviewed.

ORCID iD

Alvaro Tejerizo-Garcia http://orcid.org/0000-0002-7350-4985

\section{REFERENCES}

1 Bristow RE, Tomacruz RS, Armstrong DK, et al. Survival effect of maximal cytoreductive surgery for advanced ovarian carcinoma during the platinum era: a meta-analysis. J Clin Oncol 2002;20:1248-59.

2 Chang SJ, Bristow RE. Surgical technique of en bloc pelvic resection for advanced ovarian cancer. $J$ Gynecol Oncol 2015;26:155.

3 Tozzi R, Hardern K, Gubbala K, et al. En-bloc resection of the pelvis (EnBRP) in patients with stage IIIC-IV ovarian cancer: a 10 steps standardised technique. surgical and survival outcomes of primary vs. interval surgery. Gynecol Oncol 2017;144:564-70.

4 Clayton RD, Obermair A, Hammond IG, et al. The Western Australian experience of the use of en bloc resection of ovarian cancer with concomitant rectosigmoid colectomy. Gynecol Oncol 2002;84:53-7. 